\title{
Embedding carbon impact assessment in multi-criteria supplier segmentation using ELECTRE TRI-rC
}

\author{
Jafar Rezaei ${ }^{1}$ (D) Miłosz Kadziński² ${ }^{2}$ \\ Chrysoula Vana ${ }^{1}$. Lori Tavasszy ${ }^{1}$
}

Published online: 7 March 2017

(C) The Author(s) 2017

\begin{abstract}
In the past decade, there has been an increasing interest in green supply chain management, which integrates environmental thinking into supply chain management. Assessing a supplier's potential for improvement is very important when an organization wants to achieve certain environmental targets concerning their supply base, taking into account the limited resources available. In this paper, incorporating environmental evaluation criteria into a comprehensive supplier segmentation approach called 'supplier potential matrix' (SPM), a green supplier segmentation is proposed to segment the suppliers. Two overarching dimensions_-supplier's capabilities and supplier's willingness — are used to evaluate the supplier's green potential. The two dimensions are measured by multiple criteria. A sorting method called ELECTRE TRI-rC is used to solve the resulted multi-criteria decision-making problem. In order to make a more meaningful distinction, a simple method is also proposed to assess the suppliers with respect to the carbon footprint of the raw materials they supply. The results of this assessment are combined with the ones of the SPM, resulting in a more useful segmentation. The proposed model is applied to a sample containing the suppliers of a large international company.
\end{abstract}

Jafar Rezaei

j.rezaei@tudelft.nl

Miłosz Kadziński

milosz.kadzinski@cs.put.poznan.pl

Chrysoula Vana

celia.vana@dsm.com

Lori Tavasszy

1.a.tavasszy@tudelft.nl

1 Faculty of Technology, Policy and Management, Delft University of Technology, 2628 BX, Delft, The Netherlands

2 Institute of Computing Science, Poznan University of Technology, Poznan, Poland 
Keywords Green supply chain management - Supplier segmentation - Supplier potential matrix (SPM) - Supplier evaluation · Corporate carbon footprint · MCDM - ELECTRE TRI-rC

\section{Introduction}

In recent years, there has been a considerable shift in thinking with regard to not only improving the environmental performance of company's own processes and production activities, but also extending efforts to the entire value chain, including their supply base (Gavronski et al. 2011; Govindan et al. 2015; Gotschol et al. 2014; Dubey et al. 2015). Until now, theory in strategic supply management has been based predominantly on criteria like price, quality and delivery to assess supplier's performance (Weber 1996; Bruno et al. 2012). However, with the increased emphasis on environmental issues, the need to consider supplier relationships from a strategic and sustainable perspective has become more apparent, increasing the complexity of decision-making processes (Bai and Sarkis 2010). Green supply chain management addresses the relationship between supply chain management and the natural environment (Srivastava 2007; Zhu et al. 2013). Environmental concerns, particularly related to rapid resource depletion and climate change, have led to increased pressure on companies to conform to environmental standards and report their releases of pollutants (Gavronski et al. 2011). The gases contributing to the 'greenhouse effect', also known as greenhouse gases (GHG), have increased dramatically, due to human activities, since the beginning of the industrial revolution, and have emerged as one of the most important global issues multinationals have to face (IPCC 2007).

Even though firms have attempted to respond to this challenge by developing more ecofriendly products and services, there is still little guidance on how they can reduce their impact. According to Humphreys et al. (2003a), to manage their environmental policy efficiently, companies should make it closely connected to their purchasing activities. Researchers have suggested that diffusing environmental management techniques along the supply chain can prove to be a beneficial approach to enhancing an industry's environmental performance (Humphreys et al. 2003a; Lamming and Hampson 1996). This theory is further reinforced by the development of an internationally recognized industry standard in 2011 by World Business Council for Sustainable Development (WBCSD) and World Resources Institute (WRI), which sets the boundaries and guidelines for companies to disclose emissions along their supply chain and take action towards reducing them. Taking into account that, in a majority of cases, most emissions come from the amount of goods procured, many companies' biggest opportunities for environmental improvement lie in strategic sourcing rather than the improvement of their own operations. To date, this strategy has been underrepresented in existing literature.

This study is among the first attempts to formulate a scientific approach to segmenting suppliers on the basis of their capabilities and willingness with respect to environmental issues. While existing supplier segmentation approaches consider either the characteristics of the relationship between the buyer and the suppliers or the characteristics of the products and services supplied by the suppliers, this study proposes a novel yet simple and practical approach to combine these two sets of characteristics. That is to say, green capabilities and willingness of the suppliers to collaborate are considered as the characteristics of the relationship, and the products' carbon footprint is considered as the main characteristics of the products supplied by the suppliers. To show the high potential of our approach, the results 
of application of this approach to a subset of the suppliers of a large international chemical company are presented.

In the next section, the findings of a literature review is described. The methodology including carbon impact assessment, a sorting multi-criteria decision-making (MCDM) method, ELECTRE TRI-rC, and a weighting method, Simos-Figueira-Roy (SFR) procedure is presented in Sect.3. In Sect.4, the application of this model in a large international chemical company is presented, the results of which are discussed in Sect. 5. Finally, the conclusions and suggestions for future research are presented in Sect. 6.

\section{Literature review}

Companies segment their selected suppliers to a manageable number of segments, in order to define different strategies to manage different segments, instead of defining different strategies for individual suppliers, which is inefficient, considering a large supply base. Parasuraman (1980) was the first to introduce the concept of supplier segmentation. He proposed a stepwise procedure for the identification of supplier segments, similar to customer segments, as a way of identifying suppliers that are potentially more suitable than the current ones. Kraljic (1983), another pioneer, introduced a portfolio method to help companies deal with supply risk and disruptions by integrating purchasing function as a key element in their supply management. In his model, Kraljic considered two dimensions against which the materials purchased by the company should be assessed and classified: profit impact and supply risk. Over the years, the Kraljic matrix has become the standard in the field of purchasing portfolio models and it has inspired many practitioners and researchers to examine the possibilities of a portfolio approach for purchasing purposes (Gelderman and van Weele 2005; Caniels and Gelderman 2005; Gelderman and Semeijn 2006; Brun and Pero 2011; Padhi et al. 2012; Ferreira et al. 2015; Cox 2015). Despite its popularity, Kraljic's approach has also been the subject of serious criticism for instance, with respect to the selection of segmenting variables and the operationalization of its dimensions (Gelderman and van Weele 2005).

In an effort to overcome these inefficiencies and exploit the potential benefits of supplier segmentation, research in the field across industries has generated a variety of tools using different segmentation variables and assessment criteria (Olsen and Ellram 1997; Kaufman et al. 2000; Bensaou 1999; Tang 1999; Dyer et al. 1998; van Weele 2005; Hallikas et al. 2005; Caniels and Gelderman 2007; Svensson 2004). For example, Olsen and Ellram (1997) suggested that a second portfolio matrix, next to Kraljic's, should also be developed to analyze the supplier-buyer relationships by categorizing suppliers based on the dimensions of 'relative supplier attractiveness' and 'strength of the relationship'. Dyer et al. (1998) distinguished only two categories of appropriate supplier relationship strategies, 'strategic partnerships' and 'durable arm's-length relationships', based on product characteristics and supplier's management practices. Tang (1999) highlighting the importance of supplier-buyer relationship in strategic decision-making, suggested selecting an appropriate supplier relationship strategy based on two determining factors: 'strategic importance of the part to the buyer' and 'buyer's bargaining power'. Kaufman et al. (2000) proposed a supplier typology using the dimensions of 'technology' and 'collaboration' therefore focusing on supplier's technological capability and supplier-buyer relationship to determine an appropriate strategy per category. Svensson (2004) used the dimensions of 'supplier's commitment to buyer' and 'commodity's importance to buyer' to distinguish four groups of suppliers in the automotive industry. Luzzini et al. (2012) proposed a systematic approach to purchasing portfolios by incorporating the 
consolidated transaction cost economics into traditional portfolio approach. To some extent, their approach addresses one of the weaknesses of portfolio methods, which is their limits in terms of the operationalization of the dimensions and measuring variables. Lee and Drake (2010), and Drake et al. (2013) extended Kraljic's purchasing portfolio at the component level of a product to support business strategy. Pagell et al. (2010) extended Kraljic's model by expanding the 'profit impact' dimension to 'risk to profits, the environment and/or society'. They conclude that transaction cost theory (TCE) and resource-based theories suggest that existing portfolio models need to be changed to respond to the increased emphasis on sustainable supply chain management. For a detailed overview of the various approaches developed for the purposes of supplier segmentation and their assessment dimensions and bases till 2008, see Day et al. (2010).

A new approach to supplier segmentation called supplier potential matrix was introduced by Rezaei and Ortt (2012) which aimed to fulfill the need for a unifying conceptual framework that would include all important variables from previously proposed methods under two overarching dimensions: supplier capabilities and supplier willingness. While supplier capabilities refer to supplier's knowledge and skills, supplier's willingness refers to the characteristics, which show the motivation of supplier to engage in collaboration with buyer. The potential of a supplier is evaluated based on its capabilities and willingness to collaborate, which is why this approach is called 'supplier potential matrix' (SPM).

SPM is established based on a comprehensive set of variables (criteria) for supplier evaluation, which are grouped under the dimensions of capabilities and willingness. MCDM methods could be used to aggregate the criteria under each dimension, as a result of which each supplier is identified by two overall scores, corresponding to their capabilities and willingness. Commonly two levels are considered for each dimension: low and high, which results in a matrix with four quadrants (segments). The two overall scores (for capabilities and willingness) position each supplier in a particular segment. A few MCDM methods have been applied to this problem (Rezaei and Ortt 2013a, b; Rezaei et al. 2015; Lo and Sudjatmika 2016; Hudnurkar et al. 2016; Boujelben 2016).

In this study, the SPM is adopted for the following reasons:

- As mentioned above, most studies on supplier segmentation are based on Kraljic work. The two dimensions of Kraljic's model (supply risk, and profit impact) are used to segment the supplies and not the suppliers. This is one of the main criticisms of Kraljic's portfolio model, and its extensions, which has been also mentioned by others. For instance, Dubois and Pedersen (2002) argue that "purchasing portfolio models, by simplifying the nature and context of purchasing, fail to capture vital aspects of buyer-supplier relationships". The SPM, on the other hand, not only enables the buyer to consider the element-ofexchange characteristics (supplies), but also considers the characteristics of the suppliers and the relationship.

- While specific dimensions (and variables) have been proposed for portfolio models, the overarching dimensions of the SPM can be customized to include variables (criteria) that measure a supplier's potential to contribute to a buyer's specific strategic goals. This is particularly important for the problem under study, as here the aim is to incorporate environmental-related criteria into SPM.

- While portfolio models are criticized for the selection of segmenting variables and the operationalization of their dimensions (Gelderman and van Weele 2005), the SPM provides a basis for selecting the relevant variables. The possibility of using MCDM methods to aggregate the variables under each dimension also allows for more reliable measurement and operationalization. 
- The portfolio models view the buyer-supplier relationship more like an arm's length relationship, and do not take into account the long-term relationships between buyer and supplier, which involve a relatively high level of trust and commitment. The SPM, however, enables us to capture any type of relationship (from arm's length to partnership).

Based on the salient features of the SPM, in this study, we use this segmentation approach for green supplier segmentation. As such, we review the studies considered green/environmental issues in supply chain management. Green supply chain management (GSCM) bridges environment management and supply chain management. GSCM is an integration of environmental thinking into different aspects of supply chain management including material sourcing and selection (Srivastava 2007). Recognizing the increased pressure posed on companies due to a growing environmental concern from governments as well as the public, Lamming and Hampson (1996) were perhaps the first to suggest that environmental practices should be linked to supply chain management practices, such as supplier assessment, total quality management and collaborative supply strategies.

Noci (1997) suggested a model to support the decision-maker in the selection of the most effective supplier from an environmental viewpoint. Since then, several researchers have started developing different green supplier assessment systems, by using a variety of criteria and methods to evaluate suppliers. Handfield et al. (2002) conducted a Delphi group study to develop a rational framework of the many different environmental performance indicators they had identified and came up with ten top criteria for supplier environmental performance. Humphreys et al. (2003b) developed a framework for incorporating environmental criteria into supplier selection process distinguishing between two types of criteria (quantitative and qualitative). The framework consisted of seven environmental categories consisting of thirty variables. Lu et al. (2007) proposed a framework for evaluating the environmental performance of suppliers with respect to the main criteria materials, energy using, solid residues, liquid residues, and gaseous residues. Tuzkaya et al. (2009) built a framework for evaluating suppliers against six main environmental criteria and 31 sub-criteria. Lee et al. (2009) developed two sets of criteria and sub-criteria: one for the evaluation of conventional suppliers and one for the evaluation of green suppliers, illustrating how assessment criteria should be adjusted to serve a particular goal. Kuo et al. (2010) developed a green supplier selection using a hybrid MCDM methodology, considering the criteria of cost, quality, delivery, service, environment, and corporate social responsibility. Kannan et al. (2013) used an MCDM methodology and multi-objective programming approach to select suppliers for a green supply chain management. For their selection phase, they considered the following main criteria: cost, quality, delivery, technology capability, and environmental competency. For the main criterion environmental competency, they considered the sub-criteria pollution production, resource consumption, environmental management system, and eco-design. Govindan et al. (2013) developed a supplier assessment framework based on the three dimensions of sustainability (economic, environmental and social). Combining the studies of several previous researchers, they used four main environmental criteria (pollution production, resource consumption, eco-design and environmental management system). Hsu et al. (2013) focused on supplier selection criteria for carbon management issues rather than on broader environmental criteria, like the previous studies did. In their work, they identified 13 relevant criteria which they categorized under three dimensions: planning, implementation, and management. Perhaps the most important contribution in reviewing developed approaches in the field can be found in the work of Govindan et al. (2015), who structurally reviewed literature in green supplier evaluation and selection. For more discussion on green procurement, one may refer to Appolloni et al. (2014), and for more discussion on methods and the criteria for green sup- 
plier selection (until 2011), the interested readers are referred to the review paper (Igarashi et al. 2013). For examples of recent studies on green supplier selection, one may refer to (Dobos and Vörösmarty 2014; Sivakumar et al. 2015; Rezaei et al. 2016; Hashemi et al. 2015; Freeman and Chen 2015; Wu and Barnes 2016; Govindan and Sivakumar 2016).

Reviewing existing literature reveals an increasing popularity of incorporating environmental criteria in supplier evaluation and selection. However, existing literature is lacking systematic green supplier segmentation. In this paper, a green supplier segmentation model is developed that can help managers choose from different management approaches towards their supply base, with the specific goal of improving their environmental performance. To this end, the SPM served as the basis for segmenting suppliers. In the current study, in order to measure the two dimensions supplier capabilities and supplier willingness, with a focus on environmental issues, two categories of criteria are considered: (i) the criteria assessing supplier's capabilities in terms of reducing the carbon footprint of the raw materials they sell to the specific customer, (ii) the criteria assessing supplier's willingness to work either independently or in collaboration with the buyer towards the fulfillment of the buyer's objective, which is again the reduction of carbon footprint of the materials being bought.

\section{Methodology}

This section includes a two-part methodology. In the first part we propose a simple method to calculate the suppliers' carbon footprint and assign them to different impact categories. In the second part we use ELECTRE TRI-rC method including the SRF procedure to segment the suppliers with respect to their capabilities and willingness. We then combine the results of these two parts embedding carbon impact assessment in supplier segmentation.

\subsection{Carbon impact assessment}

Supplier $i(i=1,2, \ldots, n)$, that produces $k$ raw materials is assigned to an impact category related to the size of its contribution to the company's carbon footprint as follows.

Step 1 Calculate supplier's total carbon footprint (Total C $F_{i}$ ):

$$
\text { Total } C F_{i}=\sum_{j=1}^{k} C F_{i j}, i=1,2, \ldots, n
$$

where $C F_{i j}$ shows carbon footprint of raw material $j$ that is attributed to supplier $i$, which is calculated as follows:

$$
C F_{i j}=X_{i j} e_{i j}
$$

where $X_{i j}$ shows the purchasing volume of material $j$ from supplier $i$, and $e_{i j}\left(\mathrm{~kg} \mathrm{CO}_{2 e} / \mathrm{kg}\right.$ material) shows the cradle-to-gate emission factor of material $j$ purchased from supplier $i$.

Step 2 Sort suppliers based on total carbon footprint (Total $C F_{i}$ ) following a descending order.

Step 3 Calculate the cumulative contribution of supplier $m$ to the organization's total footprint, $F_{S m}$, as follows:

$$
F_{S m}=\frac{\sum_{i \mid i \geq m} \operatorname{Total} C F_{i}}{\sum_{i=1}^{n} \operatorname{Total} C F_{i}}
$$

where $i \succeq m$ indicates that only supplier $m$ and the suppliers that have a higher rank than supplier $m$ in Step 2 are considered. 
Step 4 Divide suppliers into impact categories based on their contribution. For example, three impact categories can be distinguish as follows:

- High impact: $F_{S i} \leq 50 \%$;

- Medium impact: $50 \%<F_{S i} \leq 80 \%$;

- Low impact: $80 \%<F_{S i} \leq 100 \%$.

A good allocation of carbon emissions that come from a company's supply base provides a solid starting point in understanding which suppliers/materials are the major contributors and where the greatest improvement margins lie.

\subsection{Assessment of suppliers with ELECTRE TRI-rC}

In this section, we present the ELECTRE TRI-rC method (Kadziński et al. 2015) that is used to assign the suppliers to a set of pre-defined and ordered classes (segments). The method constructs an outranking relation $S$ to compare the suppliers with the set of characteristic class profiles, and exploits this relation to derive for each supplier a possibly imprecise class interval it should be assigned to. ELECTRE TRI-rC is a revised version of ELECTRE TRI-C (Almeida Dias et al. 2010). The main innovation consists in using the assignment rules which identify the worst and the best class for each alternative using univocal, precise, and easily interpretable conditions (for a detailed comparison between these methods, see Kadziński et al. 2015). In what follows, we discuss the main steps of multi-criteria decision-making process that we employed to the case of this study.

The company aims to evaluate the suppliers in terms of two overarching dimensions, their willingness and capabilities. Thus, Steps 1-12 are conducted separately for each of these dimensions, and the resulting class assignments are combined in Step 13 to indicate supplier's potential to meet the buying firm's expectations.

Step 1 Determine the suppliers (alternatives) to be assessed. Let us denote the set of all suppliers by $A=\left\{a_{1}, \ldots, a_{i}, \ldots, a_{n}\right\}$.

Step 2 Define the preference ordered classes (segments) to which suppliers should be assigned: $C l_{1}, \ldots, C l_{h}, \ldots, C l_{p}$, so that $C l_{h}$ is preferred to $C l_{h-1}$ for $h=2, \ldots, p$.

Step 3 Define the consistent family of evaluation criteria $G=\left\{g_{1}, \ldots, g_{j}, \ldots, g_{m}\right\}$.

Step 4 Determine the weight $w_{j}, j=1, \ldots, m$, of all criteria. Note that in ELECTRE the intrinsic weights are interpreted as the voting powers of all criteria, indicating their relative importance (Figueira et al. 2013). Several procedures have been proposed to determine the weights in the context of outranking methods (see, e.g., Mousseau 1995; Rogers and Bruen 1998; Figueira and Roy 2002). In this study, we use the Simos-Roy-Figueira (SRF) procedure (Figueira and Roy 2002, also called the revised Simos' procedure). It is well accepted even by the non-experts in MCDM, and has been already used in many real-world applications (see, e.g., Figueira et al. 2011; Fontana et al. 2011; Siskos and Tsotsolas 2015).

The method assumes the decision-maker (DM) would rank the cards with criteria names from the least important to the most important (some criteria may be judged equally important). Then, the DM is asked to quantify the difference of importance between successive groups of criteria deemed indifferent $L_{s}$ and $L_{s+1}$ through $e_{s}$ white (empty) cards inserted between these groups. As a result, each criterion $g_{j}$ is assigned some importance rank (let us denote it by $l(j))$ so that the greater the rank, the better. Finally, the DM needs to specify a ratio $Z$ between the importance of the most and the least significant criteria denoted by $L_{\mathrm{V}}$ and $L_{1}$, respectively. These inputs, i.e., the ranks and ratio $Z$, are used to derive weights with 
Table 1 Performance table

\begin{tabular}{llllll}
\hline$A \backslash G$ & $g_{1}()$ & $\ldots$ & $g_{j}()$ & $\ldots$ & $g_{m}()$ \\
\hline$a_{1}$ & $g_{1}\left(a_{1}\right)$ & $\ldots$ & $g_{j}\left(a_{1}\right)$ & $\ldots$ & $g_{m}\left(a_{1}\right)$ \\
$\cdot$ & $\cdot$ & $\ldots$ & $\cdot$ & $\ldots$ & $\cdot$ \\
$a_{i}$ & $g_{1}\left(a_{i}\right)$ & $\ldots$ & $g_{j}\left(a_{i}\right)$ & $\ldots$ & $g_{m}\left(a_{i}\right)$ \\
$\cdot$ & $\cdot$ & $\ldots$ &. & $\ldots$ & $\cdot$ \\
$a_{n}$ & $g_{1}\left(a_{n}\right)$ & $\ldots$ & $g_{j}\left(a_{n}\right)$ & $\ldots$ & $g_{m}\left(a_{n}\right)$ \\
\hline
\end{tabular}

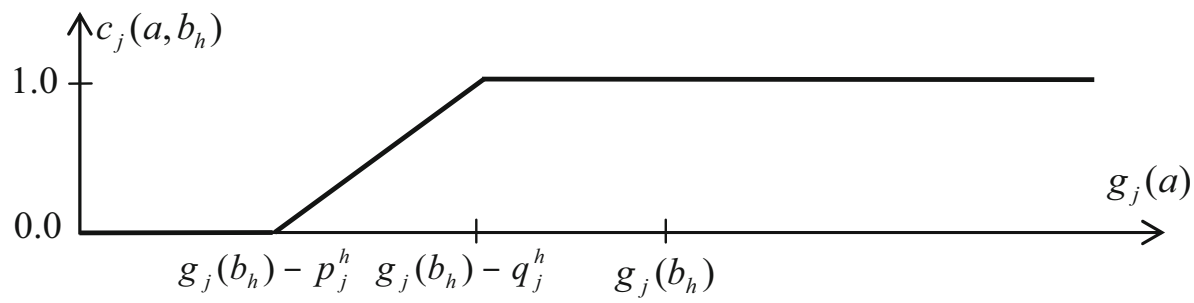

Fig. 1 The partial concordance function for ELECTRE TRI-rC

a simple and computationally efficient procedure which has been implemented in the SRF software (Figueira and Roy 2002; Corrente et al. 2016):

$$
w_{j}^{\prime}=1+\frac{(Z-1)\left[l(j)-1+\sum_{s=1}^{l(j)-1} e_{s}\right]}{v-1+\sum_{s=1}^{v-1} e_{s}} .
$$

Finally, the weights are normalized so that they sum up to one:

$$
w_{j}=\frac{w_{j}^{\prime}}{\sum_{i=1}^{m} w_{i}^{\prime}} .
$$

Step 5 Assess the performance $g_{j}(a)$ of each supplier $a \in A$ with respect to all criteria $g_{j}, j=1, \ldots, m$. As a result, the considered problem can be expressed in a matrix format as presented in Table 1. Without loss of generality, we assume that all criteria are of gain type (i.e., the greater the performance, the better).

Step 6 Specify the characteristic profile $b_{\mathrm{h}}$ for each class $C l_{\mathrm{h}}, h=1, \ldots, p$. Each profile $b_{\mathrm{h}}$ is formed from the most representative performance values for $C l_{\mathrm{h}}$ on $g_{\mathrm{j}}, j=1, \ldots, m$.

Step 7 For each criterion, define the partial concordance function $c_{j}$ through the indifference $q_{j}^{h}$ and preference $p_{j}^{h}$ thresholds. These thresholds indicate, respectively, the maximal difference between $g_{j}(a)$ and $g_{j}\left(b_{h}\right)$ that is negligible and the minimal difference justifying the strict preference. For each pair composed of an alternative and a characteristic profile, function $c_{j}$ is used to derive a partial concordance index $c_{j}\left(a, b_{h}\right)$ ranging from 0 to 1 (see Fig. 1). It quantifies a degree to which criterion $g_{j}$ agrees with the hypothesis about outranking $a S b_{\mathrm{h}}$. In what follows, we discuss how to compute the results for the comparison of alternative $a$ with profile $b_{\mathrm{h}}$, while the outcomes for an inverse pair $\left(b_{\mathrm{h}}, a\right)$ can be obtained analogously.

Step 8 Determine the comprehensive concordance index $C\left(a, b_{h}\right)$ indicating the strength of the coalition of criteria which support the hypothesis about $a$ being at least as good as $b_{h}$ on a scale between 0 and 1 : 


$$
C\left(a, b_{h}\right)=\sum_{j=1}^{m} w_{j} c_{j}\left(a, b_{h}\right)
$$

If all criteria strongly support $a S b_{\mathrm{h}}$, then $C\left(a, b_{h}\right)=1$. If none of the criteria supports this hypothesis strongly $\left(c_{j}\left(a, b_{h}\right)=1\right)$ nor weakly $\left(0<c_{j}\left(a, b_{h}\right)<1\right)$, then $C\left(a, b_{h}\right)=0$.

Step 9 Specify the veto thresholds $v_{j}^{h}, j=1, \ldots, m$, for all criteria. Veto threshold expresses the power assigned to a criterion to be against the outranking relation when the difference between $g_{j}\left(b_{h}\right)$ and $g_{j}(a)$ exceeds $v_{j}^{h}$. Thus, it is considered as a critical difference in performances such that if $a$ is worse than $b_{\mathrm{h}}$ by at least $v_{\mathrm{j}}$ for some $j=1, \ldots, m$, this is enough to invalidate the outranking relation $a S b_{\mathrm{h}}$. Formally, the result of a comparison against the veto thresholds on all criteria is quantified with the comprehensive non-discordance index:

$$
D\left(a, b_{h}\right)= \begin{cases}0 & \text { if } \exists j \in\{1, \ldots, m\}: g_{j}\left(b_{h}\right)-g_{j}(a) \geq v_{j}^{h}, \\ 1 & \text { if } \forall j \in\{1, \ldots, m\}: g_{j}\left(b_{h}\right)-g_{j}(a)<v_{j}^{h} .\end{cases}
$$

Step 10 Compute the credibility of an outranking relation by integrating the comprehensive concordance and non-discordance indices:

$$
\sigma\left(a, b_{h}\right)=C\left(a, b_{h}\right) \cdot D\left(a, b_{h}\right) .
$$

It can be interpreted as a fuzzy outranking relation. Note that if there is no veto on any criterion, then $\sigma\left(a, b_{h}\right)=C\left(a, b_{h}\right)$. Otherwise, i.e., if there is at least one criterion strongly opposing to $S$, then $D\left(a, b_{h}\right)=0 \Rightarrow \sigma\left(a, b_{h}\right)=0$.

Step 11 Specify the cutting level $\lambda$ (also called credibility threshold) which indicates the minimal value of an outranking credibility justifying the truth of a crisp outranking relation $S$ :

$$
\sigma\left(a, b_{h}\right) \geq \lambda \Leftrightarrow a S b_{h} .
$$

Verify the truth of preference $\succ$, indifference $\sim$, and incomparability $R$ relations in the following way:

$$
\begin{aligned}
& a S b_{h} \wedge \operatorname{not}\left(b_{h} S a\right) \Rightarrow a \succ b_{h}, \\
& a S b_{h} \wedge b_{h} S a \Rightarrow a \sim b_{h}, \\
& \operatorname{not}\left(a S b_{h}\right) \wedge \operatorname{not}\left(b_{h} S a\right) \Rightarrow a R b_{h} .
\end{aligned}
$$

Step 12 Apply the assignment rules of ELECTRE TRI-rC to indicate the worst $C l_{\mathrm{L}}(a)$ and the best class $C l_{\mathrm{R}}(a)$ in which alternative $a$ can be assigned. To determine $C_{\mathrm{L}}(a)$, compare $a$ successively to $b_{h}$, for $h=p-1, \ldots, 0$, seeking the first characteristic profile $b_{h}$ such that:

$$
a \succ b_{h} \wedge \sigma\left(a, b_{h+1}\right)>\sigma\left(b_{h}, a\right),
$$

and select $C l_{\mathrm{L}}(a)=C l_{\mathrm{h}+1}$. To determine $C_{\mathrm{R}}(a)$, compare $a$ successively to $b_{h}$, for $h=$ $2, \ldots, p$, seeking the first characteristic profile $b_{h}$ such that:

$$
b_{h} \succ a \wedge \sigma\left(b_{h-1}, a\right)>\sigma\left(a, b_{h}\right),
$$

and select $C l_{\mathrm{R}}(a)=C l_{\mathrm{h}-1}$. Thus, the assignment of $a$ to the class interval $C l(a)=$ $\left[C l_{\mathrm{L}}(a), C l_{\mathrm{R}}(a)\right]$ can be justified with:

- $a$ being clearly better than $b_{\mathrm{L}-1}$ and there existing sufficiently strong arguments in support of $a$ being at least as good as $b_{\mathrm{L}}$; 
- $a$ being clearly worse than $b_{\mathrm{R}+1}$ and there existing sufficiently strong arguments in support of $b_{\mathrm{R}}$ being at least as good as $a$.

In case $C l_{\mathrm{L}}(a)=C l_{\mathrm{R}}(a)$, the recommended assignment $C l(a)$ is precise. Otherwise, it is imprecise.

Step 13 Determine the potential $C l_{\mathrm{P}}(a)$ of each supplier to meet the expectations of the buying firm by combining the recommended assignments in terms of willingness and capabilities, i.e.: $C l_{\mathrm{P}}(a)=\left\{C l_{\mathrm{W}}(a), C l_{\mathrm{C}}(a)\right\}$, where $C l_{\mathrm{W}}(a)$ and $C l_{\mathrm{C}}(a)$ are the assignments from Step 12 accounting only for either willingness or capabilities, respectively.

\section{Application}

\subsection{The company}

The proposed methodology is applied to the data collected from a large international chemical company. It is a global science-based company active in health, nutrition and materials. The company provides innovative solutions to markets worldwide, like food and dietary supplements, personal care, feed pharmaceuticals, medical devices, paints, electrical and electronics, life protection, alternative energy and bio-based materials. Purchasing is a globally-operating functional group that consists of a Central Sourcing Unit and Business Group Purchasing departments, under the leadership of the Chief Purchasing Officer. This matrix organization aims for world-wide collaboration between all purchasing employees across the company. Sustainability is one of the company's growth drivers, together with high growth economies, innovation and acquisitions/partnerships. Based on the belief that sustainability will be the key differentiator value driver in the coming decades, the concept is an integral part of the company's operations, strategic actions and decisions across all functions, including purchasing. The company explicitly takes sustainability into account in the selection, evaluation and development of its suppliers.

\subsection{Assign supplier to a carbon impact category}

The methodology described in Sect.3.1 is implemented to allocate emissions to suppliers of the company and assign them to an impact category of low, medium, high. Calculating carbon emissions requires the use of two types of data: activity data and emission factors.

Activity data is a quantitative measure of a level of activity that results in GHG emissions (e.g. kg purchased, km driven, hours spent). The mass of raw materials purchased and the corresponding suppliers are extracted from the company's database and can be considered to be highly accurate and company-specific. The dataset included approximately 230 raw materials provided by 242 suppliers.

Emission factor is a factor that converts activity data into $\mathrm{GHG}$ emissions data (e.g. $\mathrm{kg} \mathrm{CO}_{2 \mathrm{e}}$ emitted per liter of fuel consumed or per $\mathrm{kg}$ of material produced) (WRI/WBCSD 2013). It is the result of a cradle-to-supplier's gate LCA and should vary when changes occur in the system. In this research, emission factors are derived from available databases that describe industry averages.

Three impact categories have been defined to distinguish among suppliers: 
- High impact suppliers (suppliers that belong in the range 0-50\% contribution): 10 suppliers;

- Medium impact suppliers (50\%-80\%): 22 suppliers;

- Low impact suppliers (80\%-100\%): 210 suppliers.

The final results for a sample of 50 suppliers are shown in Table 2.

It should be mentioned here that there is no formula to define the impact categories (the number of categories, and the cut-off points). The categorization used in this study is in line with the 80/20 Pareto principle, which is used in many managerial decisions.

\subsection{Assessment of suppliers with ELECTRE TRI-rC}

In this study, we assess 50 suppliers denoted by $A=\left\{a_{1}, \ldots, a_{50}\right\}$. The preferences and results have been co-constructed through an interactive process between the analysts and the company's buyers. The final aim consists in assigning each supplier to a pair of classes (or class intervals) associated with:

- its willingness to work towards the fulfillment of the buying company's objective which is about reducing carbon footprint of the materials the company is buying;

- its capabilities in terms of reducing the carbon footprint of the raw materials they sell to the buying company.

Their combination indicates supplier's position in the grid which is translated into supplier's potential to meet the buying company's expectations.

\section{Modeling the set of criteria}

Supplier's willingness can be defined as confidence, commitment and motivation to engage in a (long-term) relationship with the buyer. To assess supplier's willingness to work either independently or in collaboration with the buyer towards reduction of carbon footprint, we have defined the following six criteria $G^{W}=\left\{g_{1}^{w}, \ldots, g_{6}^{w}\right\}$ :

- Commitment to buyer $\left(g_{1}^{w}\right)$ a degree to which the company is perceived as an important customer by the supplier. It is reflected in how the supplier stands up to company's expectations, e.g., willing to invest some resources. Although this criterion assesses a general supplier-buyer relationship, it demonstrates the potential supplier's reaction to a demand related to sustainability.

- Commitment to sustainability $\left(g_{2}^{w}\right)$ a degree to which sustainability constitutes an important aspect in supplier's strategic development. It reflects the supplier's efforts to reduce the environmental footprint through product/process improvement, waste elimination, and cleaner technology.

- Openness to information sharing $\left(g_{3}^{w}\right)$ a degree to which the supplier is willing to share information related to the environmental performance (e.g., energy consumption) of one's operations and the carbon footprint of one's products. If such information is not available, the supplier's contribution to the company's carbon management efforts is often marginal.

- Openness to site evaluation $\left(g_{4}^{w}\right)$ a degree to which the supplier is open to the buyer's visits oriented towards the assessment process of current environmental performance and the identification of improvement areas in the supply chain. The two extreme performances correspond to refusing the audit and being already audited or having declared the openness to site evaluation.

- Trust $\left(g_{5}^{w}\right)$ a degree to which the company can rely on supplier's input, self-assessment, and fulfillment of their expectations. This criterion is particularly relevant when the exchange of sensitive information is required in order to attain the goal. 
- Communication richness $\left(g_{6}^{w}\right)$ a degree to which the supplier is willing to discuss the company's evaluation of its performance, to clarify expectations and to exploit improvement opportunities.

Supplier's capabilities are complex bundles of skills and accumulated knowledge, exercised through organizational processes that enable firms to coordinate activities and make use of their assets in different business functions that are important for the buyer. To assess the supplier's capabilities in terms of reducing the carbon footprint of the raw materials they sell to the buying company, we have defined the following nine criteria $G^{c}=\left\{g_{1}^{c}, \ldots, g_{9}^{c}\right\}$ :

- Senior management support $\left(g_{1}^{c}\right)$ a degree to which senior management supports and encourages advancements and investments in reducing the environmental impact from the processes in place and seeks for collaboration opportunities with partners alongside the supply (value) chain of one's products.

- Personnel $\left(g_{2}^{c}\right)$ a degree to which the supplier has experienced and trained personnel in monitoring, managing and communicating the environmental performance of company's operations, and this personnel can easily be tracked by the supply chain partners.

- Network $\left(g_{3}^{c}\right)$ a degree to which supplier participates in global organizations for sustainable development and collaborates with non-government organizations and external consultants to tackle environmental challenges. Criteria $g_{1}^{c}-g_{3}^{c}$ measure a degree to which the supplier has integrated sustainability in one's strategy, thus, indicating a potential for effective carbon management.

- Energy efficiency/EMS $\left(g_{4}^{c}\right)$ a degree to which supplier invests in improving energy efficiency of one's operations either by reducing the amount of energy consumed or by turning to alternative types of energy for one's operations.

- $E c o+\left(g_{5}^{c}\right)$ a degree to which supplier invests in new product development with reduced environmental footprint.

- Transport and packaging $\left(g_{6}^{c}\right)$ a degree to which the supplier invests in optimizing transportation with a consideration towards the environment and use environmentally friendly product package. Criteria $g_{4}^{c}-g_{6}^{c}$ measure supplier's green design capabilities in terms of three dimensions that directly affect carbon footprint of products at its different stages.

- External recognition $\left(g_{7}^{c}\right)$ a degree to which supplier has a good reputation in effective environmental management and has received performance awards from recognized institutions.

- Carbon disclosure $\left(g_{8}^{c}\right)$ a degree to which supplier publicly discloses the environmental performance from one's operations (e.g., sustainability report or carbon disclosure program) and how detailed and transparent the reporting is. The criterion measures whether there is an existing built-in monitoring and reporting system which increases the chances of the supplier to improve one's performance.

- Pollution control $\left(g_{9}^{c}\right)$ a degree of supplier's capabilities in reducing pollution from one's activities throughout the years. A supplier showing a continuous improvement in terms of one's environmental performance is more likely to produce the same product with a continuously improved footprint.

Overall, 20 buyers from the buying company participated in the survey which resulted in the assessment of 50 suppliers. For each criterion, we used a five point scale with 1 and 5 indicating, respectively, the worst and the best performance. The performances of 50 suppliers with respect to all 15 criteria are provided in Table 2. 
Table 2 Performances of 50 suppliers with respect to 6 willingness and 9 capabilities criteria

\begin{tabular}{|c|c|c|c|c|c|c|c|c|c|c|c|c|c|c|c|c|}
\hline \multirow[t]{2}{*}{ Supplier } & \multicolumn{6}{|c|}{ Willingness } & \multicolumn{9}{|c|}{ Capabilities } & \multirow{2}{*}{$\begin{array}{l}\text { Impact } \\
\text { category }\end{array}$} \\
\hline & $g_{1}^{w}$ & $g_{2}^{w}$ & $g_{3}^{w}$ & $g_{4}^{w}$ & $g_{5}^{w}$ & $g_{6}^{w}$ & $g_{1}^{c}$ & $g_{2}^{c}$ & $g_{3}^{c}$ & $g_{4}^{c}$ & $g_{5}^{c}$ & $g_{6}^{c}$ & $g_{7}^{c}$ & $g_{8}^{c}$ & $g_{9}^{c}$ & \\
\hline$a_{1}$ & 5 & 4 & 5 & 5 & 5 & 4 & 4 & 4 & 3 & 3 & 2 & 3 & 3 & 4 & 4 & High \\
\hline$a_{2}$ & 5 & 5 & 5 & 5 & 5 & 4 & 4 & 4 & 3 & 4 & 3 & 3 & 4 & 4 & 4 & High \\
\hline$a_{3}$ & 3 & 3 & 3 & 3 & 4 & 3 & 5 & 5 & 3 & 3 & 1 & 5 & 4 & 3 & 3 & High \\
\hline$a_{4}$ & 4 & 4 & 5 & 4 & 4 & 4 & 5 & 5 & 3 & 4 & 2 & 3 & 3 & 3 & 3 & High \\
\hline$a_{5}$ & 4 & 4 & 5 & 4 & 4 & 5 & 5 & 5 & 4 & 5 & 2 & 3 & 4 & 4 & 3 & High \\
\hline$a_{6}$ & 4 & 4 & 4 & 4 & 4 & 4 & 5 & 5 & 4 & 2 & 1 & 3 & 4 & 4 & 4 & High \\
\hline$a_{7}$ & 5 & 4 & 5 & 5 & 5 & 5 & 3 & 3 & 3 & 3 & 4 & 4 & 3 & 2 & 4 & High \\
\hline$a_{8}$ & 2 & 3 & 3 & 3 & 4 & 4 & 5 & 4 & 2 & 3 & 4 & 2 & 2 & 4 & 4 & High \\
\hline$a_{9}$ & 5 & 4 & 4 & 4 & 4 & 4 & 5 & 4 & 4 & 4 & 5 & 4 & 5 & 4 & 4 & High \\
\hline$a_{10}$ & 4 & 4 & 4 & 4 & 4 & 4 & 2 & 2 & 2 & 2 & 1 & 3 & 4 & 3 & 4 & Medium \\
\hline$a_{11}$ & 3 & 3 & 1 & 1 & 3 & 3 & 2 & 2 & 3 & 2 & 1 & 3 & 3 & 2 & 2 & Medium \\
\hline$a_{12}$ & 3 & 3 & 2 & 3 & 3 & 3 & 3 & 3 & 4 & 4 & 3 & 3 & 3 & 3 & 4 & Medium \\
\hline$a_{13}$ & 4 & 4 & 5 & 5 & 5 & 5 & 4 & 4 & 2 & 3 & 3 & 4 & 3 & 4 & 3 & Medium \\
\hline$a_{14}$ & 5 & 4 & 5 & 5 & 5 & 4 & 4 & 3 & 2 & 4 & 2 & 3 & 3 & 4 & 3 & Medium \\
\hline$a_{15}$ & 4 & 4 & 3 & 4 & 4 & 5 & 4 & 3 & 4 & 5 & 5 & 3 & 4 & 4 & 3 & Medium \\
\hline$a_{16}$ & 5 & 4 & 4 & 5 & 4 & 5 & 4 & 5 & 4 & 4 & 3 & 4 & 3 & 5 & 3 & Medium \\
\hline$a_{17}$ & 1 & 4 & 2 & 1 & 3 & 2 & 3 & 4 & 3 & 4 & 4 & 4 & 3 & 3 & 3 & Medium \\
\hline$a_{18}$ & 5 & 4 & 5 & 5 & 5 & 4 & 4 & 4 & 2 & 3 & 2 & 4 & 3 & 2 & 4 & Low \\
\hline$a_{19}$ & 5 & 5 & 5 & 5 & 5 & 4 & 4 & 4 & 3 & 4 & 2 & 3 & 4 & 4 & 4 & Low \\
\hline$a_{20}$ & 1 & 1 & 1 & 1 & 3 & 1 & 2 & 2 & 3 & 2 & 1 & 3 & 3 & 2 & 2 & Low \\
\hline$a_{21}$ & 5 & 4 & 5 & 4 & 5 & 5 & 4 & 4 & 3 & 3 & 2 & 4 & 3 & 3 & 4 & Low \\
\hline$a_{22}$ & 3 & 3 & 2 & 2 & 2 & 2 & 3 & 3 & 2 & 3 & 3 & 2 & 2 & 2 & 3 & Low \\
\hline$a_{23}$ & 3 & 4 & 3 & 3 & 4 & 4 & 4 & 4 & 3 & 3 & 4 & 3 & 4 & 3 & 3 & Low \\
\hline$a_{24}$ & 4 & 4 & 5 & 5 & 4 & 5 & 4 & 4 & 3 & 3 & 5 & 3 & 3 & 4 & 4 & Low \\
\hline$a_{25}$ & 2 & 4 & 4 & 3 & 3 & 4 & 3 & 3 & 3 & 3 & 4 & 3 & 3 & 3 & 4 & Low \\
\hline$a_{26}$ & 5 & 5 & 3 & 5 & 5 & 5 & 4 & 4 & 2 & 5 & 2 & 3 & 3 & 3 & 4 & Low \\
\hline$a_{27}$ & 4 & 3 & 4 & 4 & 5 & 3 & 3 & 3 & 2 & 4 & 3 & 4 & 3 & 3 & 3 & Low \\
\hline$a_{28}$ & 1 & 2 & 2 & 1 & 1 & 1 & 2 & 2 & 2 & 2 & 2 & 3 & 2 & 3 & 2 & Low \\
\hline$a_{29}$ & 3 & 4 & 4 & 5 & 3 & 4 & 5 & 4 & 5 & 4 & 4 & 5 & 5 & 5 & 5 & Low \\
\hline$a_{30}$ & 2 & 2 & 3 & 2 & 2 & 3 & 3 & 3 & 3 & 3 & 2 & 3 & 3 & 3 & 3 & Low \\
\hline$a_{31}$ & 5 & 5 & 3 & 5 & 5 & 5 & 5 & 5 & 5 & 5 & 5 & 5 & 3 & 3 & 5 & Low \\
\hline$a_{32}$ & 5 & 4 & 3 & 5 & 4 & 4 & 3 & 3 & 1 & 5 & 5 & 4 & 2 & 4 & 4 & Low \\
\hline$a_{33}$ & 5 & 3 & 4 & 4 & 5 & 5 & 3 & 3 & 2 & 4 & 3 & 4 & 3 & 3 & 3 & Low \\
\hline$a_{34}$ & 3 & 3 & 2 & 5 & 3 & 3 & 3 & 3 & 2 & 4 & 2 & 3 & 3 & 3 & 3 & Low \\
\hline$a_{35}$ & 4 & 3 & 3 & 3 & 4 & 4 & 3 & 2 & 2 & 4 & 3 & 3 & 2 & 2 & 3 & Low \\
\hline$a_{36}$ & 2 & 3 & 2 & 2 & 3 & 2 & 3 & 3 & 3 & 3 & 3 & 3 & 3 & 3 & 4 & Low \\
\hline$a_{37}$ & 3 & 3 & 3 & 3 & 3 & 3 & 3 & 3 & 3 & 4 & 4 & 4 & 3 & 4 & 3 & Low \\
\hline$a_{38}$ & 5 & 5 & 5 & 5 & 5 & 5 & 5 & 5 & 5 & 5 & 3 & 5 & 5 & 5 & 5 & Low \\
\hline$a_{39}$ & 3 & 3 & 3 & 5 & 3 & 3 & 3 & 3 & 2 & 4 & 2 & 3 & 3 & 3 & 3 & Low \\
\hline$a_{40}$ & 2 & 3 & 3 & 2 & 3 & 2 & 3 & 3 & 2 & 2 & 2 & 2 & 1 & 3 & 1 & Low \\
\hline$a_{41}$ & 1 & 3 & 2 & 1 & 3 & 2 & 3 & 4 & 3 & 3 & 2 & 3 & 1 & 3 & 1 & Low \\
\hline
\end{tabular}


Table 2 continued

\begin{tabular}{|c|c|c|c|c|c|c|c|c|c|c|c|c|c|c|c|c|}
\hline \multirow[t]{2}{*}{ Supplier } & \multicolumn{6}{|c|}{ Willingness } & \multicolumn{9}{|c|}{ Capabilities } & \multirow{2}{*}{$\begin{array}{l}\text { Impact } \\
\text { category }\end{array}$} \\
\hline & $g_{1}^{w}$ & $g_{2}^{w}$ & $g_{3}^{w}$ & $g_{4}^{w}$ & $g_{5}^{w}$ & $g_{6}^{w}$ & $g_{1}^{c}$ & $g_{2}^{c}$ & $g_{3}^{c}$ & $g_{4}^{c}$ & $g_{5}^{c}$ & $g_{6}^{c}$ & $g_{7}^{c}$ & $g_{8}^{c}$ & $g_{9}^{c}$ & \\
\hline$a_{42}$ & 4 & 3 & 4 & 5 & 4 & 4 & 3 & 3 & 3 & 3 & 2 & 3 & 3 & 3 & 3 & Low \\
\hline$a_{43}$ & 4 & 3 & 4 & 5 & 3 & 5 & 4 & 4 & 3 & 3 & 3 & 4 & 4 & 5 & 3 & Low \\
\hline$a_{44}$ & 1 & 3 & 2 & 1 & 3 & 2 & 3 & 4 & 3 & 3 & 2 & 3 & 1 & 3 & 1 & Low \\
\hline$a_{45}$ & 2 & 3 & 3 & 2 & 3 & 2 & 3 & 4 & 3 & 3 & 2 & 3 & 1 & 3 & 1 & Low \\
\hline$a_{46}$ & 4 & 3 & 3 & 3 & 3 & 4 & 3 & 3 & 4 & 2 & 2 & 2 & 3 & 3 & 3 & Low \\
\hline$a_{47}$ & 5 & 5 & 4 & 4 & 5 & 5 & 4 & 5 & 3 & 4 & 3 & 4 & 3 & 3 & 4 & Low \\
\hline$a_{48}$ & 2 & 3 & 3 & 2 & 3 & 2 & 3 & 3 & 3 & 3 & 2 & 3 & 2 & 3 & 2 & Low \\
\hline$a_{49}$ & 5 & 3 & 3 & 4 & 3 & 4 & 3 & 3 & 3 & 3 & 3 & 3 & 3 & 5 & 3 & Low \\
\hline$a_{50}$ & 3 & 3 & 2 & 3 & 3 & 3 & 3 & 2 & 3 & 3 & 3 & 3 & 4 & 5 & 3 & Low \\
\hline
\end{tabular}

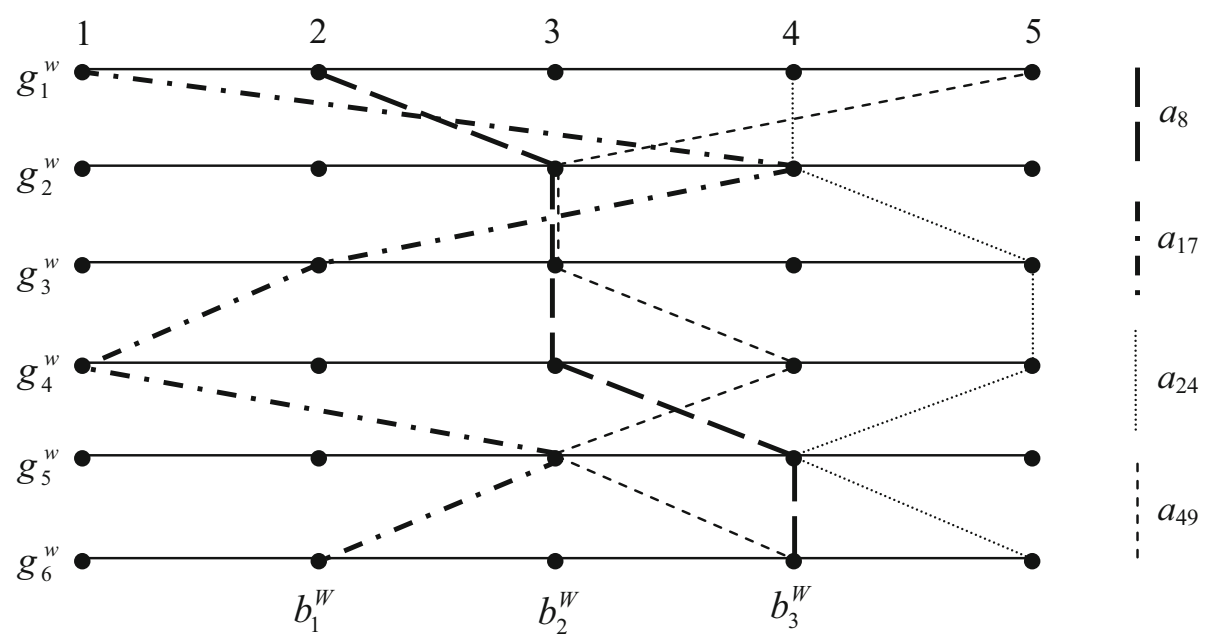

Fig. 2 Representation of the four suppliers and characteristic profiles in terms of the willingness criteria

\section{Modeling the set of classes}

The objective of the case study is to give an easily interpretable recommendation to the company about suppliers' potential to engage and maintain a partnership to achieve mutual objectives. The assessment of such potential is composed of individual perception of suppliers' willingness and capabilities. For each dimension, this perception is assessed in terms of an assignment to a set of three pre-defined and ordered classes: $\mathrm{Cl}^{W}=\left\{\mathrm{Cl}_{1}^{W}, \mathrm{Cl}_{2}^{W}, \mathrm{Cl}_{3}^{W}\right\}$ (for willingness) and $C l^{C}=\left\{\mathrm{Cl}_{1}^{C}, \mathrm{Cl}_{2}^{C}, \mathrm{Cl}_{3}^{C}\right\}$ (for capabilities). The interpretation of these classes is as follows: $C l_{1}$-low, $\mathrm{Cl}_{2}$-medium, and $\mathrm{Cl}_{3}$-high.

Each class $C l_{\mathrm{h}}$ is defined by a characteristic profile $b_{\mathrm{h}}$ composed of the most characteristic performances for this class. For our study, the performances assigned to $b_{1}$ on all criteria is 2 , for $b_{2}-3$, and for $b_{3}$ is 4 . The same parameterization has been used when assessing both willingness and capabilities. Thus defined, the characteristic profiles are distinct enough to discriminate on the assignments computed with ELECTRE TRI-rC. A graphical representation of four exemplary suppliers and characteristic class profiles for the willingness criteria 
Table 3 The order of cards with criteria names and white cards in the SFR procedure for the willingness and capabilities criteria

\begin{tabular}{|c|c|c|c|c|c|c|c|}
\hline \multicolumn{4}{|c|}{ Willingness } & \multicolumn{4}{|c|}{ Capabilities } \\
\hline Criteria & $\operatorname{Rank}^{\mathrm{a}}$ & $\begin{array}{l}\text { White } \\
\text { cards }\end{array}$ & $\begin{array}{l}\text { Normalized } \\
\text { weights }\end{array}$ & Criteria & $\operatorname{Rank}^{\mathrm{c}}$ & $\begin{array}{l}\text { White } \\
\text { cards }\end{array}$ & $\begin{array}{l}\text { Normalized } \\
\text { weights }\end{array}$ \\
\hline$g_{6}^{w}$ & 1 & & 0.042 & $g_{3}^{c}, g_{6}^{c}$ & 1 & & 0.026 \\
\hline \multirow[t]{2}{*}{$g_{5}^{w}$} & 2 & & 0.069 & $g_{9}^{c}$ & 2 & & 0.050 \\
\hline & & 1 & & $g_{8}^{c}$ & 3 & & 0.074 \\
\hline \multirow[t]{2}{*}{$g_{4}^{w}$} & 3 & & 0.122 & $g_{2}^{c}$ & 4 & & 0.098 \\
\hline & & 1 & & $g_{5}^{c}, g_{7}^{c}$ & 5 & & 0.122 \\
\hline \multirow[t]{2}{*}{$g_{3}^{w}$} & 4 & & 0.175 & & & 2 & \\
\hline & & 2 & & $g_{4}^{c}$ & 6 & & 0.193 \\
\hline \multirow[t]{2}{*}{$g_{2}^{w}$} & 5 & & 0.256 & & & 3 & \\
\hline & & 2 & & $g_{1}^{c}$ & 7 & & 0.289 \\
\hline$g_{1}^{w}$ & 6 & & 0.336 & & & & \\
\hline Total & & & 1.000 & Total & & & 1.000 \\
\hline
\end{tabular}

${ }^{\mathrm{a}} 1=$ the worst rank and $6=$ the best rank

${ }^{\mathrm{b}} \mathrm{Z}$ ratio $=8$

$\mathrm{c}_{1}=$ the worst rank and $7=$ the best rank

$\mathrm{d}_{\mathrm{Z} \text { ratio }}=11$

is provided in Fig. 2. When analyzing different criteria, all these suppliers but $a_{24}$ attain performances which are typical for at least two classes. Thus, one needs to process them using ELECTRE TRI-rC to derive a sufficiently decisive recommendation.

\section{Modeling the role of criteria}

Since the suppliers have been evaluated on a five point ordinal scale, the indifference and preference thresholds have been set to null for all 15 criteria and all characteristic thresholds.

To derive the weights of willingness and capabilities criteria, we used the SFR procedure. The rankings of criteria, the inserted white cards, and $Z$ ratios are presented in Table 3. Obviously, the greater the rank of a criterion, the more significant it is. This is reflected in the final weights. Among the willingness criteria, commitment to buyer is the most important one, whereas communication richness is the least significant criterion. Among the capabilities criteria, senior management support and network have, respectively, the greatest and the least importance.

Finally, veto thresholds are used to give each criterion a particular power to oppose to an outranking relation. For all criteria, the veto thresholds have been set in the following way:

- no supplier with the worst performance (1) on any criterion can outrank the characteristic profile of the best class whose performances on all criteria have been set to 4 ;

- the characteristic profile of the worst class whose performances on all criteria have been set to 2 cannot outrank any supplier with the best performance (5) on any criterion.

Thus, the following pairs of performances on the ordinal scale imply the veto effect: $(1,4)$, $(1,5)$, or $(2,5)$. 
Table 4 Credibility indices and class assignments obtained with ELECTRE TRI-rC for four exemplary suppliers evaluated in terms of the willingness criteria (cutting level $\lambda^{w}=0.7$ )

\begin{tabular}{|c|c|c|c|c|c|c|c|c|c|}
\hline & $b_{1}^{W}$ & $b_{2}^{W}$ & $b_{3}^{W}$ & {$\left[C l_{L}^{W}, C l_{R}^{W}\right]$} & & $b_{1}^{W}$ & $b_{2}^{W}$ & $b_{3}^{W}$ & {$\left[C l_{L}^{W}, C l_{R}^{W}\right]$} \\
\hline$a_{8}$ & $\succ$ & $\prec$ & $\prec$ & {$\left[C l_{2}^{W}, \mathrm{Cl}_{2}^{W}\right]$} & $a_{24}$ & $\succ$ & $\succ$ & $\succ$ & {$\left[\mathrm{Cl}_{3}^{W}, \mathrm{Cl}_{3}^{W}\right]$} \\
\hline$\sigma\left(a_{8}, b_{h}\right)$ & 1.00 & 0.66 & 0.11 & & $\sigma\left(a_{24}, b_{h}\right)$ & 1.00 & 1.00 & 1.00 & \\
\hline$\sigma\left(b_{h}, a_{8}\right)$ & 0.34 & 0.89 & 1.00 & & $\sigma\left(b_{h}, a_{24}\right)$ & 0.00 & 0.00 & 0.66 & \\
\hline$a_{17}$ & $\mathrm{R}$ & $\prec$ & $\prec$ & {$\left[C l_{1}^{W}, C l_{1}^{W}\right]$} & $a_{49}$ & $\succ$ & $\succ$ & $\mathrm{R}$ & {$\left[C l_{2}^{W}, C l_{3}^{W}\right]$} \\
\hline$\sigma\left(a_{17}, b_{h}\right)$ & 0.54 & 0.33 & 0.00 & & $\sigma\left(a_{49}, b_{h}\right)$ & 1.00 & 1.00 & 0.50 & \\
\hline$\sigma\left(b_{h}, a_{17}\right)$ & 0.68 & 0.74 & 1.00 & & $\sigma\left(b_{h}, a_{49}\right)$ & 0.00 & 0.50 & 0.66 & \\
\hline
\end{tabular}

\section{Assignment results}

The weights and veto thresholds are used to compare 50 suppliers against the set of characteristic profiles, and vice versa, separately in terms of willingness and capabilities criteria. The result of such comparison is quantified with the credibility of an outranking relation. In Table 4, we present such credibility degrees derived from the analysis of the willingness criteria for four exemplary alternatives.

The cutting levels validated by the experts have been selected as follows:

- for the willingness: $\lambda^{w}=0.7$; referring to the weights provided in Table 3 , the following exemplary coalitions of criteria have been judged to be strong enough to validate the truth of an outranking relation: $\left\{g_{1}^{w}, g_{2}^{w}, g_{3}^{w}\right\},\left\{g_{1}^{w}, g_{2}^{w}, g_{4}^{w}\right\}$ or $\left\{g_{1}^{w}, g_{2}^{w}, g_{5}^{w}, g_{6}^{w}\right\}$;

- for the capabilities: $\lambda^{c}=0.75$; referring to the weights provided in Table 3 , the following exemplary coalitions of criteria have been judged to be strong enough to validate the truth of an outranking relation: $\left\{g_{1}^{c}, g_{2}^{c}, g_{3}^{c}, g_{4}^{c}, g_{7}^{c}\right\},\left\{g_{1}^{c}, g_{2}^{c}, g_{4}^{c}, g_{5}^{c}, g_{8}^{c}\right\}$ or $\left\{g_{1}^{c}, g_{2}^{c}, g_{5}^{c}, g_{7}^{c}, g_{8}^{c}, g_{9}^{c}\right\}$.

In this way, $g_{1}^{w}$ and $g_{1}^{c}$ play the role of the most important criteria in the respective families because they need to agree with the outranking so that its truth is validated.

The assignment of suppliers to the pre-defined and preference ordered classes have been obtained with ELECTRE TRI-rC. In Table 4, we provide the detailed results for four exemplary suppliers in terms of the willingness class. For example:

- a precise assignment of $a_{8}$ to $C l_{2}^{W}$ can be justified with $a_{8}$ being better than $b_{1}^{W}$ and worse than $b_{2}^{W}$, but there existing sufficiently strong arguments that $a_{8}$ is at least as good as $b_{2}^{W}\left(\sigma\left(a_{8}, b_{2}^{w}\right)=0.66>\sigma\left(b_{1}^{w}, a_{8}\right)=0.34\right)$;

- a precise assignment of $a_{24}$ to $C l_{3}^{W}$ can be justified with $a_{24}$ being better than $b_{3}^{W}$;

- an imprecise assignment of $a_{49}$ to $\left[\mathrm{Cl}_{2}^{W}, \mathrm{Cl}_{3}^{W}\right]$ can be justified with $a_{49}$ being better than $b_{2}^{W}$, incomparable with $b_{3}^{W}$, and there existing non-sufficiently strong arguments supporting that $a_{24}$ is at least as good as $b_{3}^{W}\left(\sigma\left(a_{49}, b_{3}^{w}\right)=0.5 \leq \sigma\left(b_{2}^{w}, a_{49}\right)=0.50\right)$.

Overall, according to the assignment results presented in Fig. 3, ELECTRE TRI-rC provided a precise assignment for 46 and 47 out of 50 suppliers for willingness and capabilities, respectively. The imprecise two-class assignments (marked in bold in Fig. 3 ) concern: $a_{40}, a_{45}, a_{48}$, and $a_{49}$ (for willingness) and $a_{3}, a_{6}$, and $a_{32}$ (for capabilities). When it comes to willingness, the level of 27, 17, and 10 suppliers can be judged as high, medium, and low, respectively (note that the suppliers with imprecise assignments count twice). As far as the level of capabilities is concerned, 21, 27, and 5 suppliers have been judged, respectively, high, medium, and low. 


\begin{tabular}{|c|c|c|c|}
\hline $\mathrm{Cl}_{3}$ (High) & $\begin{array}{l}\text { High impact: }- \\
\text { Medium impact: } a_{10} \\
\text { Low impact: - }\end{array}$ & $\begin{array}{l}\text { High impact: } \boldsymbol{a}_{\mathbf{6}}, a_{7} \\
\text { Medium impact: } a_{13} \\
\text { Low impact: } a_{18}, a_{21}, \\
a_{27}, \boldsymbol{a}_{32}, a_{33}, a_{42}, \boldsymbol{a}_{49}\end{array}$ & $\begin{array}{l}\text { High impact: } a_{1}, a_{2}, a_{4}, \\
a_{5}, a_{6}, a_{9} \\
\text { Medium impact: } a_{14}, a_{15}, \\
a_{16} \\
\text { Low impact: } a_{19}, a_{24}, a_{26}, \\
a_{29}, a_{31}, a_{32}, a_{38}, a_{43}, a_{47}\end{array}$ \\
\hline $\mathrm{Cl}_{2}$ (Medium) & $\begin{array}{l}\text { High impact: }- \\
\text { Medium impact: } a_{11} \\
\text { Low impact: } \boldsymbol{a}_{\mathbf{4 0}}\end{array}$ & $\begin{array}{l}\text { High impact: } \boldsymbol{a}_{\mathbf{3}} \\
\text { Medium impact: } a_{12} \\
\text { Low impact: } a_{22}, a_{25}, a_{34}, \\
a_{35}, a_{37}, a_{39}, \boldsymbol{a}_{45}, a_{46}, \boldsymbol{a}_{\mathbf{4 8}}, \boldsymbol{a}_{\mathbf{4 9}}, \\
a_{50}\end{array}$ & $\begin{array}{l}\text { High impact: } \boldsymbol{a}_{3}, a_{8} \\
\text { Medium impact:- } \\
\text { Low impact: } a_{23}\end{array}$ \\
\hline \multirow[t]{2}{*}{$C l_{1}$ (Low) } & $\begin{array}{l}\text { High impact: }- \\
\text { Medium impact:- } \\
\text { Low impact: } a_{20}, \\
a_{28}, \boldsymbol{a}_{40}\end{array}$ & $\begin{array}{l}\text { High impact: }- \\
\text { Medium impact: } a_{17} \\
\text { Low impact: } a_{30}, a_{36}, a_{41}, \\
a_{44}, \boldsymbol{a}_{\mathbf{4 5}}, \boldsymbol{a}_{\mathbf{4 8}}\end{array}$ & $\begin{array}{l}\text { High impact: }- \\
\text { Medium impact:- } \\
\text { Low impact: - }\end{array}$ \\
\hline & $C l_{1}$ (Low) & $\mathrm{Cl}_{2}$ (Medium) & $\mathrm{Cl}_{3}$ (High) \\
\hline
\end{tabular}

\section{Capabilities}

Fig. 3 Supplier segmentation according to the willingness and capabilities classes obtained with the ELECTRE TRI-rC method, and their carbon impact

The combination of the willingness and capabilities assignments indicates supplier's position in the grid (see Fig. 3). It is translated into supplier's potential to meet the buying firm's expectations. The greatest number of suppliers (18) attained the highest performance in terms of two dimensions. Another 13 suppliers were judged medium with respect to both willingness and capabilities. On the other extreme, there is no supplier with low willingness and high capabilities and few suppliers with low capabilities and at least medium willingness.

\section{Integrate impact dimension in the extended segmentation grid}

Apart from their scores on capabilities and willingness criteria, suppliers have also been assessed based on their contribution to the company's carbon footprint in Sect. 4.2. This information is integrated into the segmentation tool as a third dimension. Table 2 provides the final outcome of the combined analysis, which is visualized in Fig. 3.

\section{Discussion and managerial implications}

'Senior management support' has been identified as by far the most important capability for the fulfillment of the buyer's objective (see criteria weights derived from applying SFR in Table 3). Echoing the view of many researchers in the field, experts indicated that 'senior management support' is critical when it comes to sustainability (see, e.g., Humphreys et al. 2003b; Tummala et al. 2006; Zhu et al. 2008, 2010a, b; Subramaniam et al. 2015). Since sustainability initiatives usually include high levels of investment, either with low returns or with a difficulty to clearly quantify benefits, commitment from top management is crucial in assigning resources and providing incentives to realize change (Cousins et al. 2007). Criteria related to green design have also been recognized by several researchers as being very important (Wu 
et al. 2015). Madu et al. (2002) proposed a novel approach to integrate green issues including green design in manufacturing. Bhat (1993) considers green design "the strategy to follow to remain competitive in the international markets". Green design not only can help companies reduce the environmental impact of their products and processes, but also contributes to reducing the costs (Hu and Hsu 2010). 'Energy efficiency and the existence of EMS' (as a green design criterion) has emerged as the second most important criterion when assessing supplier's capabilities to provide its customers with low-carbon products. The main reason for this is that, a large part of a product's carbon footprint is often attributed to the energy consumed during its production. It is interesting that, while Halldórsson and Kovács (2010) argue that 'energy efficiency' has received relatively less attention in the field of SCM, in this study, it is placed in the second position, which shows its practical importance, and supports Halldórsson and Kovács's (2010) argument that the concept needs further development. Supplier's 'external recognition' and the supplier's ability to come up with new 'eco+' products were found to be the third most important criteria. The least important criterion is related to supplier's environmental capabilities with regard to the 'transport and packaging' of their goods, which can be attributed to the minimal contribution of this stage in the product's carbon footprint. Experts also claimed that collaboration with external environmental partners and NGOs has much less to offer relative to the other factors, making 'network' as another least important capabilities criterion. Both these criteria have occupied the last place, despite the fact that they belong to the groups of main capabilities criteria that scored significantly higher than the rest.

A supplier's willingness to contribute to the buyer's goal has been assessed using six main criteria. 'Supplier's commitment to buyer' has been given the highest priority. Commitment is "a lasting intention to build and maintain a long term relationship" (Walter et al. 2003). It has been found that buyers and suppliers who reduce power imbalance in their relationships, due to increased commitment, are better at developing long-term partnerships (Khoja et al. 2011). 'Commitment to sustainability' has been identified as the second most important criterion because of its twofold meaning. On the one hand, suppliers who have already embraced sustainability are expected to show more enthusiasm in identifying new improvement areas in collaboration with the buyer. On the other hand, even if those suppliers show a low level of willingness for collaboration, they may still achieve improvements on their own initiative, making it worthwhile to keep them on board. The importance of commitment to sustainability has been also recognized by others (see, for example, Stuart 2011; Parisi 2013; Foerstl et al. 2015). 'Openness to information sharing' is generally considered one of the most important criteria, as it is the only way for a buyer to effectively monitor and manage carbon emissions from his supply base. One should not forget that carbon footprint is not visible upon delivery or use of the product and the buyer relies heavily on the input provided by the supplier to fulfill their carbon reduction targets. The same is true for 'openness to site evaluation', which can be regarded as one of the most effective ways of information sharing regarding supplier's environmental performance and potential improvements. The least important willingness criteria are 'trust' and 'communication richness'.

After combining the results from supplier's impact and potential assessment suppliers were mapped in the extended green segmentation grid. Looking at Fig. 3, it can be seen that the majority of the company's suppliers under the best segments characterized by both medium or high capabilities and medium or high willingness. It is also interesting to see that the worst segments (low capabilities and/or low willingness), mainly include low impact suppliers and no one belonging to high impact category. The reasons why the buying firm may choose to keep doing business with such suppliers, as long as their contribution is low, include: limited availability of alternative resources, proximity and also, very importantly, cost considerations. 


\section{Managerial implications}

The purpose of supplier segmentation is to help managers distinguish among different management approaches regarding their suppliers and provide guidance on subsequent action they should take to realize their objectives. The main management strategies when the levels of capabilities or willingness are low include: supplier substitution, vertical integration and supplier development. In this perspective, it is suggested that supplier development efforts should be linked to the model's dimensions, differentiating among efforts to improve supplier's capabilities and efforts to increase supplier's willingness, dealing with the main underlying causes of a supplier's inefficiency. Several supplier development activities have been mentioned in literature (Krause 1999; Krause et al. 1998, 2000; Modi and Mabert 2007; Krause and Ellram 1997), and categorization is suggested based on their effect on these two dimensions, as follows:

Summarizing from the literature of supplier development, the ways to improve a supplier's environmental capabilities are: (i) evaluate suppliers, (ii) increase supplier performance goals, (iii) recognize improvements by performance awards, (iv) direct involvement. We also summarize the ways to increase a supplier's willingness as: (i) apply competitive pressure through multi-sourcing, (ii) recognize improvements by performance awards, (iii) increase volume of current business, (iv) express priority considerations for future business, (v) effectively communicate benefits, (vi) direct involvement. These development strategies can be used to promote suppliers from lower segments to higher segments (Rezaei et al. 2015).

\section{Conclusion and future research}

In this study, a green supplier segmentation model was proposed that considers the two overarching dimensions of capabilities and willingness. Using three classes for each dimension, suppliers were segmented to nine segments. Suppliers' capabilities and willingness that could contribute to buyer's objective to reduce the carbon footprint are considered, which is why suppliers' emission impact is considered as well. Different criteria were taken into account to measure suppliers' capabilities and suppliers' willingness. To conduct the segmentation considering different criteria, the use of multi-criteria decision-making methods was suggested. In this paper, a sorting methodology called ELECTRE TRI-rC is used, as part of which SFR procedure is used to find the weights of the criteria. The proposed model was applied to a sample of suppliers of a large international chemical company. It is found that 'senior management support' and 'energy efficiency and the existence of EMS' are the most important capabilities for the fulfillment of the buyer's objective, while 'supplier's commitment to buyer' was found to be the most important willingness criterion. The model proposed in this paper can help companies design efficient green strategies. It also helps the companies find suppliers who need help, either in their capabilities or in their willingness to be greener. While existing literature focuses extensively on a firm's capabilities to become greener, willingness plays a very important role as well.

This research has been conducted as a case study in a manufacturing company. General applicability of the model should be further investigated in different sectors, such as the service, logistics or retail industry. Whereas, in the manufacturing industry, raw materials usually make the largest contribution to an organization's carbon footprint, in other sectors other categories, as defined by the GHG protocol (WRI/WBCSD 2013), may play a more important role, shifting attention to different types of suppliers. In that case, criteria should be adapted accordingly to represent the supplier's characteristics. Another interesting direction 
for future research is the incorporation of time variable into the model. As pointed out by Bygballe and Persson (2015) buyers and suppliers learn about each other over time. Such knowledge can be considered as an input to revise the supplier relationship management strategies, which could result in a dynamic supplier segmentation model. In this study, the definition of critical suppliers/materials used to prioritize efforts has been based solely on the size of the emissions. However, it may also be about characterizing suppliers or materials based on the likelihood of risk exposure, energy using, solid residues, liquid residues, and gaseous residues (Lu et al. 2007). Further refinement of the definition of critical suppliers is recommended to include more factors and avoid confusion in purchasing function.

Acknowledgements The work of the second author was supported by the Polish Ministry of Science and Higher Education under the Iuventus Plus program in 2016-2019 Grant Number IP2015 029674 0296/IP2/2016/74.

Open Access This article is distributed under the terms of the Creative Commons Attribution 4.0 International License (http://creativecommons.org/licenses/by/4.0/), which permits unrestricted use, distribution, and reproduction in any medium, provided you give appropriate credit to the original author(s) and the source, provide a link to the Creative Commons license, and indicate if changes were made.

\section{References}

Almeida Dias, J., Figueira, J. R., \& Roy, B. (2010). Electre Tri-C: A multiple criteria sorting method based on characteristic reference actions. European Journal of Operational Research, 204(3), 565-580.

Appolloni, A., Sun, H., Jia, F., \& Xiaomei, L. I. (2014). Green Procurement in the private sector: A state of the art review between 1996 and 2013. Journal of Cleaner Production, 85, 122-133.

Bai, C., \& Sarkis, J. (2010). Integrating sustainability into supplier selection with grey system and rough set methodologies. International Journal of Production Economics, 124(1), 252-264.

Bensaou, B. (1999). Portfolios of buyer supplier relationships. Sloan Management Review, 40(4), 35-44.

Bhat, V. N. (1993). Green marketing begins with green design. Journal of Business \& Industrial Marketing, 8(4), 26-31.

Boujelben, M. A. (2016). A unicriterion analysis based on the PROMETHEE principles for multicriteria ordered clustering. Omega (in press).

Brun, A., \& Pero, M. (2011). Assessing suppliers for strategic integration: A portfolio approach. International Journal of Business Excellence, 4(3), 346-370.

Bruno, G., Esposito, E., Genovese, A., \& Passaro, R. (2012). AHP-based approaches for supplier evaluation: Problems and perspectives. Journal of Purchasing and Supply Management, 18(3), 159-172.

Bygballe, L. E., \& Persson, G. (2015). Developing supply base strategies. IMP Journal, 9(1), 64-84.

Caniels, M., \& Gelderman, C. J. (2005). Purchasing strategies in the Kraljic matrix-A power and dependence perspective. Journal of Purchasing and Supply Management, 11(2), 141-155.

Caniels, M., \& Gelderman, C. (2007). Power and interdependence in buyer supplier relationships: A purchasing portfolio approach. Industrial Marketing Management, 36(2), 219-229.

Corrente, S., Greco, S., \& Słowiński, R. (2016). Multiple criteria hierarchy process for ELECTRE Tri methods. European Journal of Operational Research, 252(1), 191-203.

Cousins, P., Lamming, R., Lawson, B., \& Squire, B. (2007). Strategic Supply Management: Principles, Theories and Practice (1st ed.). London: Financial Times/ Prentice Hall.

Cox, A. (2015). Sourcing portfolio analysis and power positioning: Towards a "paradigm shift" in category management and strategic sourcing. Supply Chain Management: An International Journal, 20(6), 717736.

Day, M., Magnan, G. M., \& Moeller, M. M. (2010). Evaluating the bases of supplier segmentation: A review and taxonomy. Industrial Marketing Management, 39(4), 625-639.

Dobos, I., \& Vörösmarty, G. (2014). Green supplier selection and evaluation using DEA-type composite indicators. International Journal of Production Economics, 157, 273-278.

Drake, P. R., Lee, D. M., \& Hussain, M. (2013). The lean and agile purchasing portfolio model. Supply Chain Management: An International Journal, 18(1), 3-20. 
Dubey, R., Gunasekaran, A., \& Ali, S. S. (2015). Exploring the relationship between leadership, operational practices, institutional pressures and environmental performance: A framework for green supply chain. International Journal of Production Economics, 160, 120-132.

Dubois, A., \& Pedersen, A. C. (2002). Why relationships do not fit into purchasing portfolio models-A comparison between the portfolio and industrial network approaches. European Journal of Purchasing \& Supply Management, 8(1), 35-42.

Dyer, J., Cho, D., \& Chu, W. (1998). Strategic supplier segmentation: The next 'best practice' in supply chain management. California Management Review, 40(2), 57-77.

Ferreira, L. M. D., Arantes, A., \& Kharlamov, A. A. (2015). Development of a purchasing portfolio model for the construction industry: An empirical study. Production Planning \& Control, 26(5), 377-392.

Figueira, J. R., \& Roy, B. (2002). Determining the weights of criteria in the ELECTRE type methods with a revised Simos' procedure. European Journal of Operational Research, 139(2), 317-326.

Figueira, J. R., Almeida-Dias, J., Matias, S., Roy, B., Carvalho, M. J., \& Plancha, C. E. (2011). Electre Tri-C, a multiple criteria decision aiding sorting model applied to assisted reproduction. International Journal of Medical Informatics, 80, 262-273.

Figueira, J. R., Greco, S., Roy, B., \& Słowiński, R. (2013). An overview of ELECTRE methods and their recent extensions. Journal of Multi-Criteria Decision Analysis, 20, 61-85.

Foerstl, K., Azadegan, A., Leppelt, T., \& Hartmann, E. (2015). Drivers of supplier sustainability: Moving beyond compliance to commitment. Journal of Supply Chain Management, 51(1), 67-92.

Fontana, M., Morais, D. C., \& Almeida, A. T. (2011). A MCDM model for urban water conservation strategies adapting simos procedure for evaluating alternatives intra-criteria. In R. C. Takahashi, K. Deb, E. Wanner, \& S. Greco (Eds.), Evolutionary multi-criterion optimization (Vol. 6576, pp. 564-578). Berlin: Springer.

Freeman, J., \& Chen, T. (2015). Green supplier selection using an AHP-Entropy-TOPSIS framework. Supply Chain Management: An International Journal, 20(3), 327-340.

Gavronski, I., Klassen, R. D., Vachon, S., \& Nascimento, L. F. (2011). A resource-based view of green supply management. Transportation Research Part E: Logistics and Transportation Review, 47(6), 872-885.

Gelderman, C. J., \& Semeijn, J. (2006). Managing the global supply base through purchasing portfolio management. Journal of Purchasing and Supply Management, 12(4), 209-217.

Gelderman, C. J., \& van Weele, A. J. (2005). Purchasing portfolio models: A critique and update. The Journal of Supply Chain Management, 41(3), 19-28.

Gotschol, A., De Giovanni, P., \& Vinzi, V. E. (2014). Is environmental management an economically sustainable business? Journal of Environmental Management, 144, 73-82.

Govindan, K., \& Sivakumar, R. (2016). Green supplier selection and order allocation in a low-carbon paper industry: Integrated multi-criteria heterogeneous decision-making and multi-objective linear programming approaches. Annals of Operations Research, 238(1), 243-276.

Govindan, K., Khodaverdi, R., \& Jafarian, A. (2013). A fuzzy multi criteria approach for measuring sustainability performance of a supplier based on triple bottom line approach. Journal of Cleaner Production, 47, 345-354.

Govindan, K., Rajendran, S., Sarkis, J., \& Murugesan, P. (2015). Multi criteria decision making approaches for green supplier evaluation and selection: A literature review. Journal of Cleaner Production, 98, 66-83.

Halldórsson, Á., \& Kovács, G. (2010). The sustainable agenda and energy efficiency: Logistics solutions and supply chains in times of climate change. International Journal of Physical Distribution \& Logistics Management, 40(1/2), 5-13.

Hallikas, J., Puumalainen, K., Vesterinen, T., \& Virolainen, V. (2005). Risk-based classification of supplier relationships. Journal of Purchasing \& Supply Management, 11(2/3), 72-82.

Handfield, R., Walton, S. V., Sroufe, R., \& Melnyk, S. A. (2002). Applying environmental criteria to supplier assessment: A study in the application of the Analytic Hierarchy Process. European Journal of Operational Research, 141(1), 70-87.

Hashemi, S. H., Karimi, A., \& Tavana, M. (2015). An integrated green supplier selection approach with analytic network process and improved grey relational analysis. International Journal of Production Economics, $159,178-191$

Hsu, C.-W., Kuo, T.-C., Chen, S.-H., \& Hu, A. H. (2013). Using DEMATEL to develop a carbon management model of supplier selection in green supply chain management. Journal of Cleaner Production, 56(1), 164-172.

Hu, A. H., \& Hsu, C. W. (2010). Critical factors for implementing green supply chain management practice: an empirical study of electrical and electronics industries in Taiwan. Management Research Review, 33(6), 586-608.

Hudnurkar, M., Rathod, U., \& Jakhar, S. K. (2016). Multi-criteria decision framework for supplier classification in collaborative supply chains: Buyer's perspective. International Journal of Productivity and Performance Management, 65(5), 622-640. 
Humphreys, P., McIvor, R., \& Chanc, F. (2003a). Using case-based reasoning to evaluate supplier environmental management performance. Expert Systems with Applications, 25(2), 141-153.

Humphreys, P., Wong, Y., \& Chan, F. (2003b). Integrating environmental criteria into the supplier selection process. Journal of Materials Processing Technology, 138(1-3), 349-356.

Igarashi, M., de Boer, L., \& Fet, A. M. (2013). What is required for greener supplier selection? A literature review and conceptual model development. Journal of Purchasing and Supply Management, 19(4), 247263.

IPCC. (2007). IPCC 2007: Summary for policymakers. In Climate change 2007: The physical science basis. Contribution of Working.

Kadziński, M., Tervonen, T., \& Figueira, J. F. (2015). Robust multi-criteria sorting with the outranking preference model and characteristic profiles. Omega, 55, 126-140.

Kannan, D., Khodaverdi, R., Olfat, L., Jafarian, A., \& Diabat, A. (2013). Integrated fuzzy multi criteria decision making method and multi-objective programming approach for supplier selection and order allocation in a green supply chain. Journal of Cleaner Production, 47, 355-367.

Kaufman, A., Wood, C., \& Theyel, G. (2000). Collaborations and technology linkages: A strategic supplier typology. Strategic Management Journal, 21(6), 649-663.

Khoja, F., Adams, J., \& Kauffman, R. (2011). The inside story of relationship development: Power asymmetry in a buyer-supplier relationship. International Journal of Integrated Supply Management, 6(1), 73-91.

Kraljic, P. (1983). Purchasing must become supply management. Harvard Business Review, (September/October), 109-117.

Krause, D. R., Handfield, R. B., \& Scannell, T. V. (1998). An empirical investigation of supplier development: Reactive and strategic processes. Journal of Operations Management, 17(1), 39-58.

Krause, D. (1999). The antecedents of buying firms' efforts to improve suppliers. Journal of Operations Management, 17(2), 205-224.

Krause, D., \& Ellram, L. (1997). Critical elements of supplier development: The buying-firm perspective. European Journal of Purchasing and Supply Management, 3(1), 21-31.

Krause, D., Scannel, T., \& Calantone, R. (2000). A structural analysis of the effectiveness of buying firm's strategies to improve supplier's performance. Decision Sciences, 31(1), 33-55.

Kuo, R. J., Wang, Y. C., \& Tien, F. C. (2010). Integration of artificial neural network and MADA methods for green supplier selection. Journal of Cleaner Production, 18(12), 1161-1170.

Lamming, R., \& Hampson, J. (1996). The environment as a supply chain management issue. British Journal of Management, 7(Supplement s1), S45-S62.

Lee, A. H., Kang, H.-Y., Hsu, C.-F., \& Hung, H.-C. (2009). A green supplier selection model for high-tech industry. Expert Systems with Applications, 36(4), 7917-7927.

Lee, D. M., \& Drake, P. R. (2010). A portfolio model for component purchasing strategy and the case study of two South Korean elevator manufacturers. International Journal of Production Research, 48(22), 6651-6682.

Lo, S. C., \& Sudjatmika, F. V. (2016). Solving multi-criteria supplier segmentation based on the modified FAHP for supply chain management: A case study. Soft Computing, 20(12), 4981-4990.

Lu, L. Y., Wu, C. H., \& Kuo, T. C. (2007). Environmental principles applicable to green supplier evaluation by using multi-objective decision analysis. International Journal of Production Research, 45(18-19), 4317-4331.

Luzzini, D., Caniato, F., Ronchi, S., \& Spina, G. (2012). A transaction costs approach to purchasing portfolio management. International Journal of Operations \& Production Management, 32(9), 1015-1042.

Madu, C. N., Kuei, C., \& Madu, I. E. (2002). A hierarchic metric approach for integration of green issues in manufacturing: A paper recycling application. Journal of Environmental Management, 64(3), 261-272.

Modi, S., \& Mabert, V. (2007). Supplier development: Improving supplier performance through knowledge transfer. Journal of Operations Management, 25(1), 42-64.

Mousseau, V. (1995). Eliciting information concerning the relative importance of criteria. In P. M. Pardalos, Y. Siskos, \& C. Zopounidis (Eds.), Advances in multicriteria analysis, vol. 5 of nonconvex optimization and its applications (pp. 17-43). Dordrecht: Kluwer Academic.

Noci, G. (1997). Designing "green vendor" rating systems for the assessment of a supplier's environmental performance. European Journal of Purchasing and Supply Management, 3(2), 103-114.

Olsen, R. F., \& Ellram, L. M. (1997). A portfolio approach to supplier relationships. Industrial Marketing Management, 26(2), 101-113.

Padhi, S. S., Wagner, S. M., \& Aggarwal, V. (2012). Positioning of commodities using the Kraljic Portfolio Matrix. Journal of Purchasing and Supply Management, 18(1), 1-8.

Pagell, M., Wu, Z., \& Wasserman, M. E. (2010). Thinking differently about purchasing portfolios: An assessment of sustainable sourcing. Journal of Supply Chain Management, 46(1), 57-73. 
Parasuraman, A. (1980). Vendor segmentation: An additional level of market segmentation. Industrial Marketing Management, 9(1), 59-62.

Parisi, C. (2013). The impact of organisational alignment on the effectiveness of firms' sustainability strategic performance measurement systems: An empirical analysis. Journal of Management \& Governance, 17(1), 71-97.

Rezaei, J., \& Ortt, R. (2012). A multi-variable approach to supplier segmentation. International Journal of Production Research, 50(16), 4593-4611.

Rezaei, J., \& Ortt, R. (2013a). Multi-criteria supplier segmentation using a fuzzy preference relations based AHP. European Journal of Operational Research, 225(1), 75-84.

Rezaei, J., \& Ortt, R. (2013b). Supplier segmentation using fuzzy logic. Industrial Marketing Management, 42(4), 507-517.

Rezaei, J., Wang, J., \& Tavasszy, L. (2015). Linking supplier development to supplier segmentation using Best Worst Method. Expert Systems with Applications, 42(23), 9152-9164.

Rezaei, J., Nispeling, T., Sarkis, J., \& Tavasszy, L. (2016). A supplier selection life cycle approach integrating traditional and environmental criteria using the best worst method. Journal of Cleaner Production, 135, $577-588$.

Rogers, M., \& Bruen, M. (1998). A new system for weighting environmental criteria for use within Electre III. European Journal of Operational Research, 107(3), 552-563.

Siskos, E., \& Tsotsolas, N. (2015). Elicitation of criteria importance weights through the Simos method: A robustness concern. European Journal of Operational Research, 246(2), 543-553.

Sivakumar, R., Kannan, D., \& Murugesan, P. (2015). Green vendor evaluation and selection using AHP and Taguchi loss functions in production outsourcing in mining industry. Resources Policy, 46(1), 64-75.

Srivastava, S. K. (2007). Green supply-chain management: A state-of-the-art literature review. International Journal of Management Reviews, 9(1), 53-80.

Stuart, H. J. (2011). An identity-based approach to the sustainable corporate brand. Corporate Communications: An International Journal, 16(2), 139-149.

Subramaniam, N., Wahyuni, D., Cooper, B. J., Leung, P., \& Wines, G. (2015). Integration of carbon risks and opportunities in enterprise risk management systems: Evidence from Australian firms. Journal of Cleaner Production, 96, 407-417.

Svensson, G. (2004). Supplier segmentation in the automotive industry: A dyadic approach of a managerial model. International Journal of Physical Distribution and Logistics Management, 34(1), 12-38.

Tang, C. S. (1999). Supplier relationship map. International Journal of Logistics Research and applications: A Leading Journal of Supply Chain Management, 2(1), 39-56.

Tummala, V. R., Phillips, C. L., \& Johnson, M. (2006). Assessing supply chain management success factors: A case study. Supply Chain Management: An International Journal, 11(2), 179-192.

Tuzkaya, G., Ozgen, A., Ozgen, D., \& Tuzkaya, U. (2009). Environmental performance evaluation of suppliers: A hybrid fuzzy multi-criteria decision approach. International Journal of Environmental Science and Technology, 6(3), 477-790.

van Weele, A. (2005). Purchasing \& supply chain management: Analysis, strategy, planning and practice. London: Thomson Learning.

Walter, A., Müller, T. A., Helfert, G., \& Ritter, T. (2003). Functions of industrial supplier relationships and their impact on relationship quality. Industrial Marketing Management, 32(2), 159-169.

Weber, C. A. (1996). A data envelopment analysis approach to measuring vendor performance. Supply Chain Management: An International Journal, 1(1), 28-39.

WRI/WBCSD. (2013). Technical Guidance for Calculating Scope 3 Emissions (Supplement to the Corporate Value Chain Accounting and Reporting Standard. WRI/WBCSD.

Wu, C., \& Barnes, D. (2016). An integrated model for green partner selection and supply chain construction. Journal of Cleaner Production, 112(3), 2114-2132.

Wu, K. J., Liao, C. J., Tseng, M. L., \& Chiu, A. S. (2015). Exploring decisive factors in green supply chain practices under uncertainty. International Journal of Production Economics, 159, 147-157.

Zhu, Q., Dou, Y., \& Sarkis, J. (2010a). A portfolio-based analysis for green supplier management using the analytical network process. Supply Chain Management: An International Journal, 15(4), 306-319.

Zhu, Q., Geng, Y., \& Lai, K. H. (2010b). Circular economy practices among Chinese manufacturers varying in environmental-oriented supply chain cooperation and the performance implications. Journal of Environmental Management, 91(6), 1324-1331.

Zhu, Q., Sarkis, J., Cordeiro, J. J., \& Lai, K. H. (2008). Firm-level correlates of emergent green supply chain management practices in the Chinese context. Omega, 36(4), 577-591.

Zhu, Q., Sarkis, J., \& Lai, K. H. (2013). Institutional-based antecedents and performance outcomes of internal and external green supply chain management practices. Journal of Purchasing and Supply Management, 19(2), 106-117. 